\title{
La ciudadanía en disputa: La colectividad alemana ante el Estado argentino entre fines del XIX y principios del XX
}

Reseña de: Benjamin Bryce (2019).Ser de Buenos Aires: alemanes, argentinos y el surgimiento de una sociedad plural 1880-1930. Buenos Aires: Editorial Biblos. 336 páginas

Tomás Schierenbeck

t_schierenbeck@hotmail.com

Instituto de Investigaciones en Humanidades y

Ciencias Sociales (UNLP - CONICET). Facultad de

Humanidades y Ciencias de la Educación. Universidad

Nacional de La Plata, Argentina

Cita sugerida: Schierenbeck, T. (2021). La ciudadanía en disputa: La colectividad alemana ante el Estado argentino entre fines del XIX y principios del XX [Revisión del libro Ser de Buenos Aires: alemanes, argentinos y el surgimiento de una sociedad plural 1880-1930 por B. Bryce]. Sociohistórica, 48, e152. https://doi.org/10.24215/18521606e152

La búsqueda por comprender y convertir en narrativa las experiencias y proyectos de la comunidad germanoparlante en Buenos Aires entre fines del siglo XIX y mediados del XX ha constituido uno de los objetivos más buscados por parte de ciertos investigadores cuyo ámbito de producción ha sido el hemisferio norte. Enfocándose en distintos recortes temporales y en diferentes temáticas, esta serie de estudios ha dado cuenta, principalmente, de las repercusiones tanto de la Primera y Segunda Guerra Mundial dentro de la comunidad germanoparlante como del intercambio material e inmaterial entre ambos espacios geográficos. 
La obra de Benjamin Bryce, publicada en español por la Editorial Biblos dentro de su colección Argentina Plural, y titulada Ser de Buenos Aires: alemanes, argentinos y el surgimiento de una nación plural (1880-1930), nos invita a indagar de modo novedoso no sólo sobre distintos proyectos de instituciones y grupo de individualidades por "crear una comunidad alemana duradera en Buenos Aires" (Bryce, 2019, p. 23), sino también a reflexionar sobre la metodología de trabajo que hasta el momento los investigadores han establecido con respecto a la comunidad alemana en la región rioplatense. En este sentido, la recepción de noticias desde Europa, el diagnóstico sobre ellas y la percepción que tenían las grandes personalidades e instituciones europeas como de la comunidad con respecto a Alemania se ven sobredimensionadas y percibidas, por nuestro autor, como el único relato posible y existente en estas investigaciones. Ello inhibía -es lo que Bryce se propone vindicar aquí- la aparición de la voz de los propios sujetos con sus experiencias y proyectos particulares, pero principalmente como ciudadanos activos de un nuevo entramado social plural, el de Buenos Aires a principios del siglo XX. En este sentido, Bryce (2019) plantea que existe "una serie de suposiciones implícitas o declaraciones explicitas acerca de la unidad intrínseca de este grupo; también hay una tendencia a reproducir las categorías aplicadas por los líderes de las comunidades, por los nacionalistas en Alemania y los datos censales" (p. 32). En contrario a estas perspectivas de análisis, el autor nos propone superar las categorías étnicas esquemáticas y preconcebidas para comprenderlas como "circunstanciales, superpuestas y contradictorias", y advierte que "la identidad étnica es algo construido en diálogo con el contexto circundante" (Bryce, 2019, p. 33). Así, tener en cuenta las experiencias y las expectativas de los sujetos nos permite dar cuenta del modo en el que los protagonistas de su libro, como los líderes religiosos luteranos y católicos, los empresarios adinerados y la comunidad educativa germanoargentina, comprendieron su presente y estimaron tanto su futuro como el de su "comunidad" de modo diferente, a partir de sus propias necesidades. La hibridación entre tradiciones del "Allá-Entonces" y los intereses del "Aquí-Ahora" nos indican que "uno podía participar en una comunidad étnica y, a la vez, participar en otras comunidades que reflejaran la propia clase social, la identidad de género, la sexualidad, la profesión, los pasatiempos o el vecindario" (Bryce, 2019, p. 37).

El corpus general del libro se estructura en seis capítulos, aunque con una disciplina argumentativa en común. Un minucioso trabajo de archivo, desde la Biblioteca Nación de Maestros hasta distintos organismos europeos, interacciona con un aparato conceptual y de estudios de caso que le permite a Bryce ejercer un constante ejercicio comparativo entre las experiencias de distintas comunidades étnicas en Buenos Aires y en Europa del Este.

En el capítulo uno, "Bienestar social, paternalismo y construcción de la colectividad alemana", Bryce analiza de qué modo los inmigrantes adinerados se autoproclamaron líderes de la comunidad mediante un aparato de instituciones y programas que establecían una relación Beneficiario-Benefactor con los demás miembros del colectivo (Bryce, 2019). Lo interesante en este análisis es que el autor no se limita simplemente a mencionar cómo era el funcionamiento de espacios como El Hospital Alemán (1878), El Hogar de Mujeres Alemanas (1896) o La Sociedad de Beneficencia(1916), entre otros, sino que nos invita a comprender cómo estos mismos espacios colectivos funcionaron como catalizadores de los intereses de aquellos autoproclamados líderes, estimulando un específico sentido de ciudadanía caracterizada por la organización familiar, los roles de género y una sexualidad femenina correspondientes al imaginario burgués decimonónico. Procuraban, a su vez, mediante el aparato de asistencia social, la reproducción y supervivencia de la fuerza de trabajo étnicamente organizada, que en su mayoría -estimulada por los propios programas de empleo organizados por estas instituciones- obraba dentro del entramado industrial de la misma colectividad; por ejemplo, en la Cervecería Quilmes fundada en 1888 por Otto Bemberg. Sin embargo, Bryce no se detiene aquí sino que estipula que este mismo entramado de contención y reproducción de relaciones de clase y de género también les sirvió a aquellas figuras de la colectividad alemana para mostrar una imagen de unidad y "moralidad" dentro de las altas esferas de la sociedad porteña que les permitía promocionar sus propios roles como líderes y ganar estatus social en ella (Bryce, 2019). 
Los capítulos dos, tres y cuatro se refieren tanto a la comunidad educativa germano-argentina como a su relación con el sistema educativo nacional y los programas culturales incentivados por el Imperio alemán en su política internacional. Así, en "Infancia, lengua y el surgimiento de una sociedad plural”, Bryce analiza el surgimiento y configuración de la red de escuelas germano-argentinas que hacia 1930 había alcanzado las 10 instituciones. En ellas, aprendían más de 2200 alumnos, de los cuales el 77 \% había nacido en territorio nacional (Bryce, 2019). En este sentido, el autor analiza las preocupaciones de los padres y educadores por "promover el idioma alemán y los elementos de la cultura alemana", que se complementaba con el deseo de "preparar a los alumnos para vivir en la Argentina" (Bryce, 2019, p. 115); es decir educarlos cívicamente como argentinos. La aparición de una cultura hibrida en las segundas generaciones no es un punto menor en el análisis del autor, quien mediante los informes, por ejemplo, de la Escuela Cangallo y fuentes fotográficas, observa cómo en las aulas se complementaba los cuadros de los próceres nacionales junto al Kaiser Guillermo. Igualmente, se estimulaba un sentido de pertenencia dual mediante la celebración de las fechas patrias nacionales, del mismo modo que con festivales que rememoraban ciudades y regiones germanas de donde provenían los padres (Heimat). Asimismo, las escuelas bilingües son también comprendidas aquí como espacios que buscaron normativizar, bajo los mismos patrones que las asociaciones de beneficencia, las conductas de los escolares. Permitieron la construcción y reproducción de un sentido de comunidad ampliado, sustentado por las actividades asociativas (organizadas por las mujeres de la colectividad) y los programas de becas que, mediante colectas y donaciones de los estratos más altos de la comunidad comprendidas por el autor como una nueva herramienta de sostenerse como líderes-, se organizaban con el propósito de incluir en las aulas al mayor número posible de hijos y nietos de migrantes a pesar de su condición económica.

En el capítulo tres, denominado "La retórica de la ciudadanía", Bryce analiza la relación entre las instituciones bilingües y el Consejo Nacional de Educación. En este sentido, expone cómo la normativa estatal que se sustentaba en y auspiciaba un ideal cultural monolingüe, como el del hispanismo reivindicado durante inicios del siglo XX por los intelectuales nacionales, se enfrentaba con la realidad material de no tener la infraestructura suficiente para otorgarle una plaza educativa a cada niño de la ciudad de Buenos Aires. Bryce analiza aquí cómo las escuelas bilingües de las colectividades más numerosas en la ciudad pudieron ocupar aquel vacío a través de instituciones autónomas que cumplían con los planes de estudio y exámenes nacionales al mismo tiempo que funcionaban como espacios de promoción de una lengua y de una cultura extranjeras. El punto interesante se encuentra en dar cuenta de cómo las comunidades migrantes, mediante sus instituciones educativas, promocionaron un discurso alternativo de ciudadanía que, al mismo tiempo que debilitó "muchas de las políticas culturales postuladas por más de un integrante del Consejo Nacional de Educación” (Bryce, 2019, p. 173), ayudó a que, \# a diferencia de sociedades como la estadounidense y la canadiense\# no desapareciera el pluralismo cultural que la sociedad argentina conservó hasta mediados del siglo XX (Bryce, 2019).

En el cuarto capítulo, llamado “¿Una nación sin fronteras? Intereses locales y ambiciones imperiales”, Bryce analiza mediante un exhaustivo trabajo archivístico, que intercala de modo artero los Anuarios de los colegios Bilingües, periódicos destinados a los docentes como el Die Deutsche Schule im Auslande e informes de organismos alemanes como el Ministerio de Relaciones Exteriores y la Asociación para la Germanidad en el Exterior, cómo la comunidad educativa argentino-alemana reclamó distintos programas de enseñanza y de subsidios. También se benefició del estatus que otorgaba estar en relación con el Imperio alemán, al presentarse ante estos organismos como instituciones que "salvaguardaban la germanidad" y que pertenecían a una comunidad etnocultural sin fronteras, a pesar de que la comunidad educativa se alejaba del nacionalismo estimulado por los programas culturales alemanes del que era beneficiaria y promocionaba otro estilo de educación para los escolares. 
Los capítulos cinco y seis titulados "la religión transatlántica y las fronteras de la comunidad" y "La retórica de la religión” respectivamente, se encargan de una temática hasta el momento poco estudiada en la historiografía nacional: las esferas religiosas de la colectividad. Aquí, Bryce analiza las conexiones financieras y transatlánticas que posibilitaron al Alto Consistorio Protestante, al igual que a las Órdenes católicas germanas, asentarse y desplegar sus propias instituciones en la región rioplatense. Asimismo, da cuenta de la retórica que envolvía ambas misiones religiosas, por la cual las instituciones protestantes se autoproclamaban como misioneras de la tradición luterana y de la germanidad -en este sentido, como portavoces del Imperio alemán en el extranjero- en peligro en el subcontinente católico, mientras el catolicismo germano, que se insertó rápidamente dentro de la iglesia nacional, auspiciaba la posibilidad de practicar el culto en la lengua materna de la propia colectividad. Además, se analizan los proyectos de ciudadanía ligados a la preservación lingüística y del cristianismo -en contraofensiva al ideario liberal del Estado argentino- que ambas entidades religiosas estimularon en instituciones como los Hogares para Niños o en las actividades parroquiales, del mismo modo que se ponen en consideración las distintas problemáticas que estas instituciones tuvieron que enfrentar; por ejemplo, la búsqueda por estimular que las segundas y terceras generaciones permanecieran en la cristiandad y preservasen la lengua de sus ancestros, y que, al mismo tiempo, construyeran un sentido de pertenencia con la Argentina.

En líneas generales, la obra de Bryce cumple con lo propuesto: dar cuenta no sólo de que la propia comunidad alemana actuó en interacción con Europa sino también de que sus miembros desarrollaron, a partir de sus propias ambiciones económicas, políticas y culturales, distintos proyectos en el ámbito local. Se constituyeron como actores activos en la sociedad porteña al proponer, junto con las demás colectividades étnicas, un proyecto de sociedad alternativo en el que la etnicidad y la ciudadanía podían complementarse en un espacio plural. Una forma de ciudadanía diferente tanto de la estipulada por el Estado nacional argentino como de la del Ministerio de Relaciones Exteriores alemán y los intelectuales germanos respecto a las colonias alemanas en el extranjero. Se trata de un valor que hasta el momento se encontraba eclipsado en investigaciones anteriores.

\section{RefERENCIAS}

Bryce, B. (2020). Ser de Buenos Aires: alemanes, argentinos y el surgimiento de una sociedad plural 1880-1930. Buenos Aires: Editorial Biblos. 